
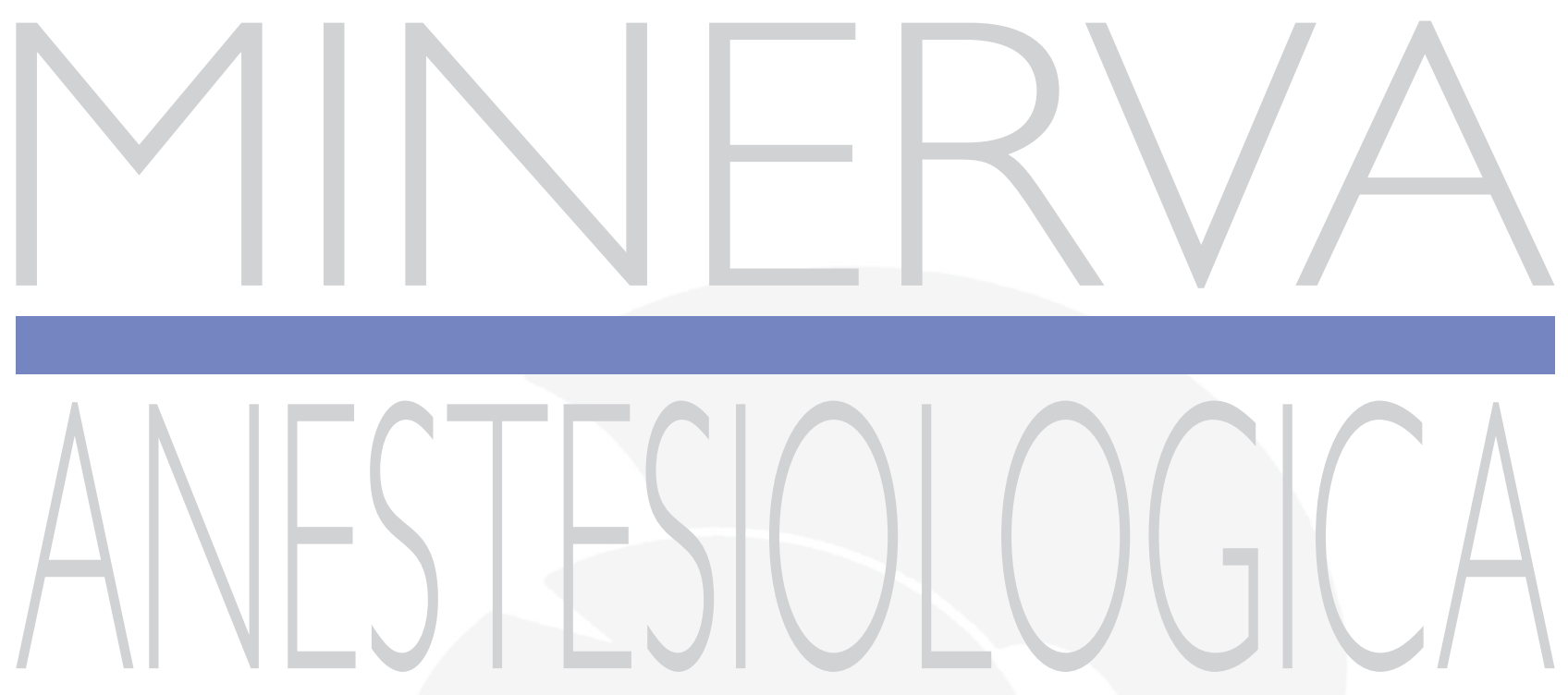

OFFICIAL JOURNAL OF ITALIAN SOCIETY OF ANESTHESIOLOGY, ANALGESIA, RESUSCITATION AND INTENSIVE CARE (SIAARTI)

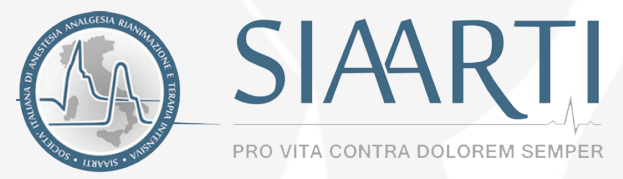

VOLUME $85 \cdot$ No. $8 \cdot A \cup G U S T 2019$

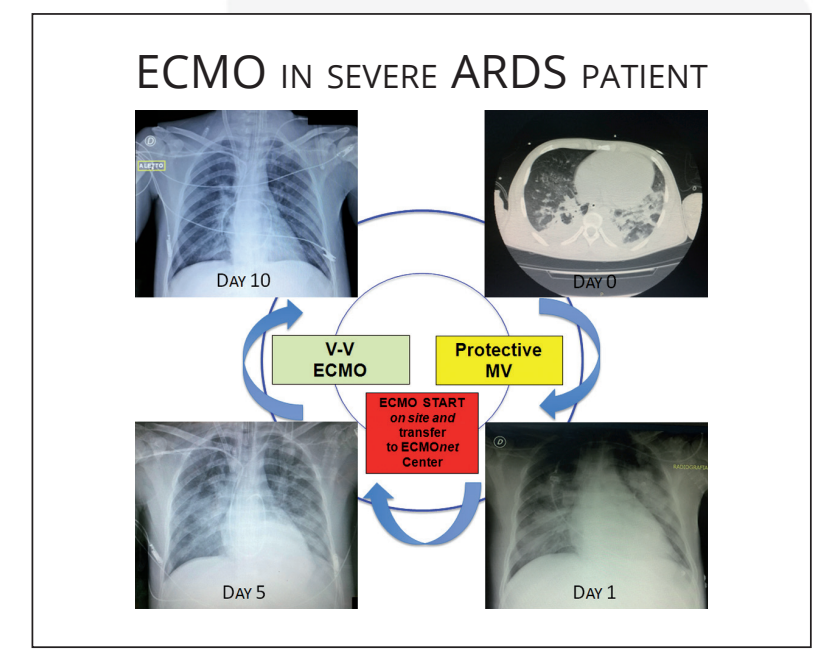

$E D|Z| O N|\cdot M| N E R V A \cdot M E D \mid C A$ 


\title{
Opioid use in addiction: swinging between pain under-treatment and opioids harms
}

\author{
Silvia NATOLI * \\ Department of Clinical Science and Translational Medicine, Tor Vergata University, Rome, Italy \\ *Corresponding author: Silvia Natoli, Department of Clinical Science and Translational Medicine, Tor Vergata University, Via Mont-
} pellier 1, 00133 Rome, Italy. E-mail: silvia.natoli@uniroma2.it

$\mathrm{W}$ ould you ever restrict opioids when needed for pain relief in an acute setting? I suppose not. However, knowing that your patient has a drug addiction, you might probably suspect drug-seeking. Consequently, you might want to restrict opioid prescription. And how would you deal with a patient with opioid use disorders (OUD) and chronic pain claiming that opioids are the only treatment that helps? Well, this is definitely a "challenging situation."

Indeed, drug addicts display an abnormal pattern of opioid use characterized by craving and continued use despite harm. As we conceive addiction as a crime rather than a disease caused by neuroplastic modification of the reward system induced by the drug continuous intake, ${ }^{1}$ we perceive patients with OUD asking for pain relief as manipulative. ${ }^{2}$ However, they can be falsely more demanding due to a tolerance to opioids ${ }^{3}$ or to an enhanced pain sensitivity. ${ }^{4}$

In this issue of Minerva Anestesiologica, Pergolizzi et al. 5 also define this as a "challenging situation" to underline the clinical challenge of treating pain in the context of addiction and to avoid stigmatization. Indeed, a clinician's misconceptions about opioids or prejudice toward OUD may cause unethical undertreatment. ${ }^{6}$

Managing chronic pain is complicated, compared to other chronic conditions. There is no objective measure for pain assessment and often there is no evidence of tissue injury. Also ben- efits and harms of therapy rely on subjective report. Nevertheless, chronic pain patients desperately seek relief from their suffering, a condition which is worsened by the negative emotional and behavioral reaction that pain related altered-cognition triggers. ${ }^{7}$

As the epidemic of prescription opioids abuse has emerged in the United States, so has it echoed in Europe 8,9 This generated an atmosphere of "witch hunt" that induces clinician to restrict opioids although indicated, fearing the risk of harm, including the risk to induce addiction. The proportion of patients who develop OUD when treated with opioids is unknown. Previous reports claimed that $0.03 \%$ of patients receiving opioids developed addiction. ${ }^{10}$ Recently, a study assessing DSM-V criteria for OUD in patients receiving opioids for chronic pain found that $28.1 \%$, $9.7 \%$, and $3.5 \%$ displayed mild, moderate and severe OUD respectively. ${ }^{11}$ Iatrogenic opioid addiction, however, is rare in patients without pre-existing predispositions ${ }^{12}$ such as emotional trauma, prolonged distress and psychiatric disorders, although these are more frequent in chronic pain patients. ${ }^{13}$

Uncertainty is increased by the lack of evidence of efficacy of opioids for chronic pain. ${ }^{14}$ However, the absence of evidence is not an evidence of absence. Indeed, patients report that opioids reduce pain, improve function and quality of life. ${ }^{15}$ Consequently, the FDA has re- 
quested to conduct research to prove long-term opioids' effectiveness. ${ }^{16}$

The opioid epidemic described in the USA is a far more complex phenomenon than addiction induced by opioid medical use. Misuse and diversion account for more than $50 \%$ of opioid-related deaths. ${ }^{17}$ Of note, one risk factor for overdose is higher doses of prescribed opioids. ${ }^{18}$ The USA experience, however, must be a warning and a teaching for European physicians. The analysis of the epidemic has led to the development of strategies to curb opioid abuse. These rely firstly upon the assessment of the risk for abuse potential through validated questionnaires, including screening of pre- and comorbid substance abuse and aberrant drug related behaviors along with psychosocial comorbidities and genetic predisposition (family history), to be administered before opioid prescription. Secondly, a close monitoring of patients for opioid abuse through screening tools while on opioids along with government prescription drug monitoring programs are advocated. ${ }^{19}$ Moreover, the development of multimodal pain-relieving strategies could reduce the overall opioid dose, as demonstrated in the acute postoperative setting. ${ }^{20,21}$

While awaiting scientific evidence of efficacy and safety we must aim at ensuring the access of chronic pain patients to a comprehensive care, including but not limited to an appropriate use of opioids and encompassing psychological support and physiotherapy. Indeed, despite all guidelines in this field advocate a multimodal pain management, pain care in most countries relies completely on pharmacologic solutions, mainly because the reimbursement system favors the use of medications alone.

Pending the possibility of a more inclusive approach, in the setting of "challenging situations," the vade mecum by Pergolizzi et al. is a useful tool to uniform a systematic approach that helps clinician decision-making process to tailor care on the basis of each patient's needs. Meanwhile, all stages of medical education need an exhaustive training in pain treatment, since training in this area has historically been scarce. Moreover, "challenging situations" demand effective communication skills enabling clinicians to adopt a welcoming attitude that facilitates an honest discussion about substance use, without moral or paternalistic attitudes.

Only education enables a finely-tuned approach to care.

\section{References}

1. Di Chiara G. Nucleus accumbens shell and core dopamine: differential role in behavior and addiction. Behav Brain Res 2002;137:75-114.

2. van Boekel LC, Brouwers EP, van Weeghel J, Garretsen HF. Healthcare professionals' regard towards working with patients with substance use disorders: comparison of primary care, general psychiatry and specialist addiction services. Drug Alcohol Depend 2014;134:92-8.

3. Merrill JO, Rhodes LA, Deyo RA, Marlatt GA, Bradley KA. Mutual mistrust in the medical care of drug users: the keys to the "narc" cabinet. J Gen Intern Med 2002;17:327-33.

4. Laulin JP, Célèrier E, Larcher A, Le Moal M, Simonnet G. Opiate tolerance to daily heroin administration: an apparent phenomenon associated with enhanced pain sensitivity. Neuroscience 1999;89:631-6.

5. Pergolizzi JV Jr, Lequang JA, Passik S, Coluzzi F. Using opioid therapy for pain in clinically challenging situations: questions for clinicians. Minerva Anestesiol 2019;85:899-908.

6. Coluzzi F, Bifulco F, Cuomo A, Dauri M, Leonardi C, Melotti RM, et al. The challenge of perioperative pain management in opioid-tolerant patients. Ther Clin Risk Manag 2017;13:1163-73.

7. Wright AR, Gatchel RJ. Occupational musculoskeletal pain and disability. In: In: Turk DC, Gatchel RJ, editors. Psychological Approaches to Pain Management: A Practitioner's Handbook. Guilford Press; 2002. p. 349-64.

8. Volkow ND, Jones EB, Einstein EB, Wargo EM. Prevention and Treatment of Opioid Misuse and Addiction: A Review. JAMA Psychiatry 2019;76:208-16.

9. Häuser W, Schug S, Furlan AD. The opioid epidemic and national guidelines for opioid therapy for chronic noncancer pain: a perspective from different continents. Pain Rep 2017;2:e599.

10. Porter J, Jick H. Addiction rare in patients treated with narcotics. N Engl J Med 1980;302:123.

11. Boscarino JA, Hoffman SN, Han JJ. Opioid-use disorder among patients on long-term opioid therapy: impact of final DSM-5 diagnostic criteria on prevalence and correlates. Subst Abuse Rehabil 2015;6:83-91.

12. Rosenblum A, Marsch LA, Joseph H, Portenoy RK. Opioids and the treatment of chronic pain: controversies, current status, and future directions. Exp Clin Psychopharmacol 2008;16:405-16.

13. Marshall B, Bland MK, Hulla R, Gatchel RJ. Considerations in addressing the opioid epidemic and chronic pain within the USA. Pain Manag 2019;9:131-8.

14. Chou R, Turner JA, Devine EB, Hansen RN, Sullivan $\mathrm{SD}$, Blazina I, et al. The effectiveness and risks of long-term opioid therapy for chronic pain: a systematic review for a National Institutes of Health Pathways to Prevention Workshop. Ann Intern Med 2015;162:276-86.

15. Manchikanti L, Kaye AM, Knezevic NN, McAnally H, Slavin K, Trescot AM, et al. Responsible, safe, and effective 
prescription of opioids for chronic non-cancer pain: American Society of Interventional Pain Physicians (ASIPP) guidelines. Pain Physician 2017;20(2S):S3-92.

16. Dyer O. US opioid epidemic: FDA demands studies of whether opioids do control chronic pain. BMJ 2019;364:1959.

17. Hall AJ, Logan JE, Toblin RL, Kaplan JA, Kraner JC, Bixler D, et al. Patterns of abuse among unintentional pharmaceutical overdose fatalities. JAMA 2008;300:2613-20.

18. Dunn KM, Saunders KW, Rutter CM, Banta-Green CJ, Merrill JO, Sullivan MD, et al. Opioid prescriptions for chronic pain and overdose: a cohort study. Ann Intern Med 2010;152:85-92.
19. Kaye AD, Jones MR, Kaye AM, Ripoll JG, Jones DE, Galan V, et al. Prescription Opioid Abuse in Chronic Pain: An Updated Review of Opioid Abuse Predictors and Strategies to Curb Opioid Abuse (Part 2). Pain Physician 2017;20(2S):S111-33.

20. Cata JP, Bugada D, De Andrés J. Opioid less perioperative care. Minerva Anestesiol 2017;83:315-20.

21. Rupniewska-Ladyko A, Malec-Milewska M, Kraszewska E, Pirozynski M. Gabapentin before laparoscopic sleeve gastrectomy reduces postoperative oxycodone consumption in obese patients: a randomized double-blind placebo-controlled trial. Minerva Anestesiol 2018;84:565-71.

Conflicts of interest.-The authors certify that there is no conflict of interest with any financial organization regarding the material discussed in the manuscript.

Comment on: Pergolizzi JV, Lequang JA, Passik S, Coluzzi F. Using opioid therapy for pain in clinically challenging situations: questions for clinicians. Minerva Anestesiol 2019;85:899-908. DOI: 10.23736/S0375-9393.19.13321-4

Manuscript accepted: June 12, 2019. - Manuscript revised: June 7, 2019. - Manuscript received: April 1, 2019.

(Cite this article as: Natoli S. Opioid use in addiction: swinging between pain under-treatment and opioids harms. Minerva Anestesiol 2019;85:819-21. DOI: 10.23736/S0375-9393.19.13767-4) 